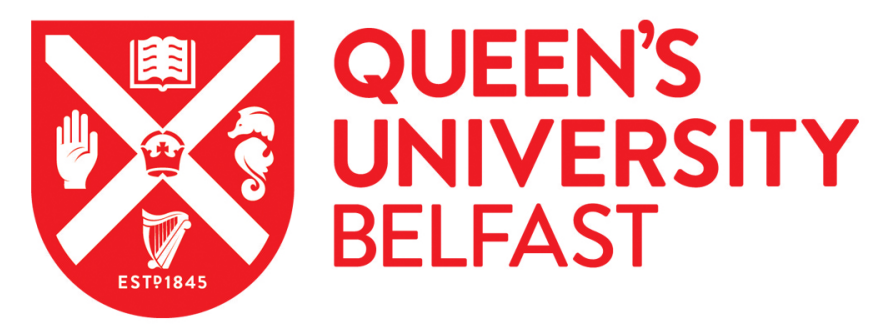

\title{
Research ethics committees: values and power in higher education
}

McAreavey, R., \& Muir, J. (2011). Research ethics committees: values and power in higher education. International Journal of Social Research Methodology, 14 (5), 391-405.

https://doi.org/10.1080/13645579.2011.565635

\section{Published in:}

International Journal of Social Research Methodology

\section{Document Version:}

Peer reviewed version

Queen's University Belfast - Research Portal:

Link to publication record in Queen's University Belfast Research Portal

\section{Publisher rights}

This is an Accepted Manuscript of an article published by Taylor \& Francis in International Journal of Social Research Methodology on 13 June 2011, available online: http://www.tandfonline.com/doi/abs/10.1080/13645579.2011.565635

\section{General rights}

Copyright for the publications made accessible via the Queen's University Belfast Research Portal is retained by the author(s) and / or other copyright owners and it is a condition of accessing these publications that users recognise and abide by the legal requirements associated with these rights.

Take down policy

The Research Portal is Queen's institutional repository that provides access to Queen's research output. Every effort has been made to ensure that content in the Research Portal does not infringe any person's rights, or applicable UK laws. If you discover content in the Research Portal that you believe breaches copyright or violates any law, please contact openaccess@qub.ac.uk. 


\section{Research Ethics Committees: values and power in higher education}

\section{Introduction}

There is widespread dissatisfaction with the ethical review model that prevails in the modern university as part of the research governance process. The activities of panels providing ethical clearance for research have proved to be a particular source of discontent. These panels are known as Research Ethics Committees in the United Kingdom, Institutional Review Boards (IRBs) in the United States, and by various other titles elsewhere in the world (see Israel and Hay, 2006, for a full account). This paper considers the experiences of applicants and REC members within the ethical review process, drawing on the literature and on the authors' experiences. We ask whether differences in values, interests and power can ever be resolved so that a collaborative approach to ethical review may be incorporated into a renewed academic research culture. The alternative, we suggest, is the increasing alienation of social researchers from anything to do with 'ethics', with potentially serious consequences for the ethical standards of social research.

While it is fair to say that scepticism is flourishing, two key stances appear to exist among academics in the current regulatory environment. On the one hand a group of researchers has positioned themselves in opposition to RECs, as expressed most prominently by Hammersley (2009). Other researchers, while recognising the limitations of RECs, have somewhat pragmatically conceded that the existence of RECs is an immovable object and something with which it is better to engage than to ignore. They argue that failure to contribute to the emerging discourse risks dealing with ever more restrictive frameworks governing research practice (Cannella and Lincoln, 2007; Connolly and Reid, 2007). It is in the spirit of the latter that this paper is written. 
How did we get down this road of dissatisfaction? Why is the ethical regulation model so riddled with problems? Is there any way in which ethical review can be rescued and turned into a valuable part of the social research process? These are the questions that we seek to answer in the course of this article as we engage with the development of RECs specifically and of research ethics more broadly. We begin with a discussion of the difference between research ethics and research governance, along with an account of the design and ownership of RECs. We then offer a multiple perspective on ethics by presenting our particular experiences. The paper concludes by asking whether a more collaborative approach may be able to bridge the widening gap between ethical review and ethical practice in higher education, or whether 'playing the game' is the more realistic future option.

\section{Research ethics: dilemmas of design and ownership}

To behave ethically means to protect others, minimise harm, and 'increase the sum of good in the world' (Israel and Hay, 2006: 2). 'Research ethics' has been defined as: 'the moral principles guiding research, from its inception through to completion and publication of results and beyond...' (ESRC 2010:40). It would be extremely rare for a social researcher to set out to behave unethically. Indeed as Hammersley (2009) points out, the ESRC emphasise that 'almost without exception, social science research in the UK has been carried out to high ethical standards' (ESRC 2005:1). While useful guidance for researchers is provided through the ethical codes of professional bodies (e.g. SRA, 2003; BSA, 2004), their inevitable inadequacy for addressing the detail of ethical dilemmas in the field has been highlighted (de Laine, 2000; Punch, 1998). These standards lack weight; they merely advocate principles (Humphries, 2000) and are self-regulating (Kent et al., 2002). RECs, on the other hand, assume a gatekeeping role in that they seek to control research practice by requiring researchers to expose their 
intended research practices to the scrutiny of their peers. A REC has been defined as 'a multidisciplinary, independent body charged with reviewing research involving human participants to ensure that their dignity, rights and welfare are protected. The independence of a REC is founded on its membership, on strict rules regarding conflict of interests, and on regular monitoring of and accountability for its decisions (ESRC 2010: 40). The ESRC's Research Ethics Framework does not 'seek to impose a detailed model for ethics evaluation and conduct' (ESRC 2010:3), instead it provides basic principles along detailed guidance on minimum requirements. These outline a role for RECs within research organisations as part of an ongoing, transparent process of review, approval and governance that is 'proportionate to the potential risk' (ESRC 2010:4). Put like this, there should be no objection to RECs and, indeed, the experience of peer review should make a positive contribution to the research process. Therefore we have to ask why the implementation of ethical scrutiny has incurred such hostility.

RECs typically reflect a core value of academic freedom that requires the involvement of academics in institutional governance through activities such as setting standards, determining curriculum and participating in committees. Indeed collegiality, shared community, autonomy and mutual support are greatly cherished as fundamental values of academia and something to which academics aspire. It is into this context that systems of regulation and control are increasingly being used within the University. They are employed as a means of achieving greater transparency and compliance towards external stakeholders including government agencies specifically and society more generally. Evident through standardised approaches admonished from the top in relation to institutional governance, they are manifest through practices relating to teaching standards and in committees such as Research Ethics Committees. The current approach offers a process that is deemed less than satisfactory; some would even question whether it is ethical (van den Hoonard 2002; Lincoln and Tierney 2004; Hemmings 2006; 
Hammersley 2009). RECs, while typically comprising academic staff, meet requirements set centrally by university administrators. We contend that the different priorities of bureaucrats (administrative prudence) and academics (rigorous research inquiry) is problematic. Disputes over consent, questions of research detail and design, concerns around certainty and ambiguity, and fundamental epistemological and disciplinary clashes; are just some of the practical matters that arise following applications for approval from RECs. It is somewhat of a paradox then that, despite the high ethical standards of social research, the rise of ethical regulation has led to researchers taking part in what are, technically, deceitful practices as far as the REC is concerned (Dolan, 1999; Truman 2003; Warlow, 2004; Tolich and Fitzgerald 2006; Richardson and McMullan 2007).

However, there is no suggestion in the literature that RECs themselves intentionally behave unethically. Rather the contention is that they follow a model resulting in inappropriate treatment of applicants. It is the framework that is at fault (Hammersley, 2009). Some authors have reflected on how to create more enabling RECs that better understand and respect the research process and support the autonomy of the individual researcher in the field. This 'balance between controlling and enabling' (Richardson and McMullan, 2007:1128) and 'bridging the space between conduct and compliance' (Israel and Hay, 2006: 131 ) is grounded in the acknowledgement of the need to engage with RECs, to ensure they operate effectively and, at the very least, do no damage. It advocates the cultivation of 'practical academic acumen' (Hemmings, 2006: 17) through training in policies, procedures and different research methodologies. Even Hammersley (2009), in his critical article on the impact of RECs on social research, suggests that they may provide a forum for discussion and advice on ethical research practice. Therefore social researchers do not dismiss the need for an ethical element to research practice; rather, the search continues for appropriate models and processes. 


\section{The rise and rise of Research Ethics Committees}

There have been two major driving forces in the increasing emphasis on research governance and the associated proliferation of RECs: one rooted in instances of deception; and the other in shifting institutional ideologies in relation to the University. First, known incidents of deception are rare but have been shocking enough to cause institutional reform (Kent et al., 2002). In the UK, the most influential episodes involved the scandal of unauthorised use of human tissue for research at Bristol Royal Infirmary and Alder Hey Children's Hospital in Liverpool during the 1990s (Truman 2003; Boden et al. 2009). Even though medical ethics committees were operational at this time, having been set up in the 1960 s to review pharmaceutical clinical trials, infant body parts were being retained without parental knowledge and consent (Hedgecoe, 2008; Boden et al. 2009). Rather than attempt to resolve social relations between relevant parties, the response was to further expand the regulatory framework within health, resulting in significant impact on other areas of research (Boden et al. 2009; ESRC 2005 and 2010).

The second imperative has been change within higher education. Governments are keen to encourage mass higher education within an increasingly competitive globalised economy and as a result student numbers have substantially increased. Standardisation is also an issue, as exemplified through treaties such as the Bologna Declaration ${ }^{1}$ in Europe. Meanwhile in the UK a quality assurance agenda is promoted by the Dearing Report and has been accused of fuelling suspicion, mistrust and resistance (Gosling 2004; Shortland 2004). One major fallout from these sea changes has been the rise of research governance and ethical regulation. Accordingly bureaucracy has risen in universities, for instance within the UK university managers increased by $33 \%$ between 2004 and 2009 (Higher Education Statistics

\footnotetext{
${ }^{1}$ http://ec.europa.eu/education/higher-education/doc1290 en.htm Last accessed 8th August 2010.
} 
Agency 2005; 2011). Consequently universities have been described as stifling values within this increasingly regulatory framework of 'policed zones' (Scott, 2004: 439).

Some of these managers are responsible for overseeing ethical review processes, this being closely connected to university revenue and academic progression: universities are under pressure to maximise grant income and individual academics cannot advance in their careers without a track record of successful funding applications. Increasingly ethical review is required before research grants are awarded. The connection between gaining ethical approval and gaining research funding for social researchers has been strengthened in the UK by the ESRC's requirement for projects to be subjected to ethical scrutiny as part of their Research Ethics Framework (ESRC, 2005 and 2010). Academics have thus been compelled to embark on what is considered by many the charade that is ethical regulation (Coomber, 2002; Israel and Hay, 2006; Tolich and Fitzgerald, 2006; Connolly and Reid, 2007). And so as Israel and Hay (2006) argue, researchers adopt a strategic approach by taking into account what they believe are the assumptions of the ethics committee. This involves participating in a review process which the researcher understands is often wholly unsuitable for reviewing the research in question, but necessary if that individual wishes to get on and do the research (Tolich and Fitzgerald, 2006:73). Tactics may include using the language of the committee, modifying the research design to gain approval, modifying research design following approval without gaining further permission for the changes, calling studies 'audits' rather than research so that they do not require approval, and the use of what researchers perceive to be deficient research designs (Dolan, 1999; Coomber, 2002; Warlow 2004; Richardson and McMullan, 2007). In short, researchers learn how to play the ethics game; 'the applicant tells the ethics review committee what they want to hear' (Tolich and Fitzgerald, 2006:73). But within these regulatory approaches ethics are not clear cut: it remains ambiguous how researchers are to 
prioritise between conflicting rights and duties such as achieving informed consent and undertaking covert research (White, 2009; Richardson and McMullan, 2007).

There are concerns in some quarters over the de-professionalisation that accompanies the increased regulation and auditing approach to ethics (Tolich and Fitzgerald, 2006; White, 2009). van den Hoonaard (2002) describes the 'moral panic' generated by ethics committees, as disproportionate claims are made about the potential harm to research participants. RECs are promoted as furthering the greater good of society in that they seek to minimise harm and maximise benefits. Actually they are about fear and risk within large-scale bureaucracies; a means of showing that universities take reasonable care to manage ethical issues and therefore to protect their interests. As Scott (2004) points out, one of the consequences of this increased management has been the redefinition of ethical issues as matters of process rather than being fundamental to the mission of the academy. Or put another way, it would appear that philosophical debates on matters pertaining to morals, ethics, standards and principles have been sidelined, if not entirely replaced, with the creation of procedures, rules and regulations and so we have witnessed the transmogrification of research ethics to research governance. Boden et al. (2009) starkly demonstrate how modern ethical bureaucracy is a chimera that masks hidden power and is far removed from critical debate on ethical conduct.

\section{Who 'owns' ethics?}

The more abstract question of who 'owns' ethics is bound to arise in a process in which the ideologies of academic freedom and administrative control collide. There are four key actors in the process: researchers, administrators, funders and research participants. It is accepted that, ultimately, responsibility for ethical practice lies with researchers (ESRC, 2005 and 2010; Richardson and McMullan, 2007). However, the parameters of ethical regulation are now being set through the demands of 
funders such as the ESRC so that '[o]verall responsibility for ensuring that research is subject to appropriate ethics review and approval lies with the research organisation which employs the individual or individuals who conduct the research' (ESRC, 2010:10). The reality behind the enabling tone of the ESRC is that engaging with RECs is compulsory for research active academic staff in UK universities because prestigious Research Council grants cannot be obtained without formal ethical approval. Finally, there is very little or no place within the ethical debate for research participants, who may have different views on what is ethical (Truman, 2003; Graham et al., 2007; Hurdley, 2010; Grinyer, 2004) but who cannot participate in the ethical review process unless they make a post hoc formal complaint to the university or to a funding body. Without their involvement it is difficult to understand their experiences, perceptions and interests (Kent et al., 2002:11).

These issues are important if we are to understand the dynamics of RECs. On the one hand their membership comprises active researchers, often with a community or lay representative. On the other, they operate within an institutional governance structure. The 'rarefied space' (Truman 2003: para 42) of the ethics committee is thus far removed from that of research practice where real people with personal stories, particular circumstances and different morals exist. The values of researchers can be obscured and the power of administrators can prevail. The clash of values between academics and administrators is at the heart of current difficulties. Whereas in the past universities engaged in normative debates on ethics, the instrumental process of ethical monitoring appears now to have taken precedence (Scott, 2004). The practical concerns of research governance, including institutional risk management, have become equated with 'ethics'. In other words ethical regulation is a technological and social process, centred on issues of power and culture (Boden et al. 2009). We strongly believe that philosophical deliberations on ethics must be nurtured despite the output-led environment of regulation and bureaucracy that pervades the modern university; hence our question whether there is any way in 
which the pragmatic components of ethical review can be rescued and turned into a valuable part of the social research process.

\section{(Conflicting) Ideological perspectives}

A particular problem with the REC framework is that it has been heavily influenced by the natural sciences, particularly medical research (Hemmings, 2006; Tolich and Fitzgerald, 2006; Connolly and Reid, 2007). Consequently one of the problems for social scientists is that RECs are premised on positivist epistemology (Yearley, 2005). For instance, the English implementation framework (Department of Health, 2004) is held up as a model, even though it has been criticised for its 'ritualistic adherence to ethical procedures' such as standardised forms (Sin, 2005:279). Subsequently it is unable to address the nature of qualitative methodologies and so is contrary to the interests of both researchers and the researched within the social sciences (Ramcharan and Cutliffe, 2001; Kent et al., 2002). It is acknowledged widely that the current controlling environment is unlikely to nurture reflexivity, empowerment or facilitation (Cannella and Lincoln, 2007:318; Connolly and Reid, 2007; White, 2009); however Crow et al. (2006) presents a dissenting view, finding that in some cases the process can enhance reflexivity.

The ethical review process commodifies the whole concept of research; it is perceived as something that can be bought with a research grant, undertaken as planned, and delivered to the funder from the production line. But as Flyvberg (2001) points out, analysis of the social sciences involves issues of values and power, within the context of the use of different epistemologies. There is a great 'range of positions and voices that influence conceptualisations of ethical practices' (Cannella and Lincoln 2007:318). How therefore can a medical model of ethical review be applied across all disciplines? The irony of the current predominant model of review is that if researchers believe that ethics have been accounted for 
through the REC, they may fail to engage in ongoing ethical reflexivity in the field (Tolich and Fitzgerald 2006; Hammersley 2009), thus damaging ethical practice once researchers have 'passed' the ethical review stage.

The ethical review process appears to be flawed for several reasons. Firstly it deals with research proposals that outline anticipated future research activity rather than describing actual events. Secondly it is a mandatory and procedural activity within academic life. These features clash with the open-ended nature of social research and with the autonomous nature of academic practice; they create tension between ethical regulation and ownership and also between ethical reflection and practice. We continue by providing four examples of our encounters with ethical research practice and RECs, revealing differences in values, interests and power which cannot be reduced to a simple division between academics and administrators. We describe this section as 'a multiple perspective' due to the different roles we experienced: REC member, REC Chair, applicant to a REC, lecturer with responsibility for students' ethics applications, student dissertation supervisor, and university administrator.

\section{Ethical research practice and Research Ethics Committees: a multiple perspective}

\section{Legitimacy and legitimation of RECS}

We have described the way in which academics 'play the game' by adopting strategies to obtain ethical approval and have shown that RECs are frequently not regarded with much respect within academic circles. These factors were evident in our own School when we were appointed to its fledgling REC. As junior academics, still on probation, we had no alternative but to accept our nominations. Neither of us had a particular research specialism in ethical matters and both of us were relatively inexperienced 
researchers, having completed our PhDs and several small projects but without the more extensive research profile of senior colleagues. We found the majority of REC members were similarly inexperienced. Even the then Chair, from a different School, was fairly new to the academic sector.

This combined lack of experience created problems. After basic training, it was a question of learning on the job and working out for ourselves what we wanted the REC to be. We instigated changes to the terms of reference to allow applicants to attend the REC; we appointed a new lay member; and we organised a briefing session on how to apply for ethical approval - which very few staff attended; we sought advice from the University Ethics Committee on specific applications and on our procedures. Our intention was that the REC would become a forum for debate on ethical issues and that we would implement the university guidelines in a collegiate and sympathetic manner thereby garnering support from academic colleagues while also embracing core academic values. During this time, one of us was appointed as Chair, which we welcomed as we thought it would give us more autonomy to develop and implement the vision. The experience of the School REC described here covers the authors' membership experience, one of whom was a member for three years while the other was involved over a two year period. The REC met roughly three times a year although several special meetings were convened to discuss applications.

Working together as a committee was not always easy. A major issue was that members with natural and physical science backgrounds found it hard to understand qualitative research methods. For example, on one occasion a member requested an applicant to submit a list of the questions that would be asked in life-history interviews. Life history research aims to engage in conversations with individuals on topics of mutual interest to explore personal experiences (Cole and Knowles, 2001). It would therefore be impossible for a life-history researcher to present a list of anticipated questions in advance 
of conducting the research. More than a straightforward lack of expertise among committee members (as suggested by Hedgecoe, 2008), this translated to a structural problem: the REC review form specifically stated that questionnaires should be supplied, and we had to argue that this was inappropriate. This is an example of a conflict between deeply seated epistemological and ontological positions of researchers (Boden et al. 2009).

A second controversial application involved issues of informed consent and comments on methodology. The applicant, a senior member of staff, felt that these comments were inappropriate and lay outside the remit of the REC. During a particularly hostile meeting, it was established that the staff member was indignant that a REC composed of researchers from different disciplines, not all of whom had a qualitative research background, was critiquing the proposed methodology. It cannot have helped that the committee members were all junior staff, although this was not made explicit during the confrontation. Subsequently that same academic copied correspondence to the Head of School and made it clear in discussions that this was because the individual felt that personal individual research integrity and competency had been questioned by the REC. The incident revealed the poor image and the lack of legitimacy of the REC within the School.

Reflective of questions raised elsewhere (Hammersley, 2009; Connolly and Reid, 2007), the issue of the RECs' remit on methodology lingered. While discussions amongst committee members revealed a strongly held view that inappropriate methodology was an ethical issue, we did encounter several other objections from applicants to the REC on having their methodology critiqued. In the end we conceded ground and commented on methodology in an advisory capacity rather than as a condition of ethical approval. This case illustrates the divisive nature of the ethical review process with colleagues being driven to engage in power struggles. 
After a couple of years it became clear that our vision for the School REC was not working: our authority was not accepted and it was perceived by our colleagues as a policing exercise. Therefore we successfully proposed to our Head of School that the REC Chair should be a more senior member of staff. Our experience shows that REC members may seek to behave responsibly, but that in order to be effective their role must be recognised and respected by peers. In our case, even with endorsement from the Head of School and the central committee, there was insufficient legitimation of the REC and so colleagues did not accept that the members had the credibility to pass judgement on their research proposals.

This example shows that clashes of values and interests do not only occur between academics and administrators. As REC members, we would have said that our values were the same as those of our colleagues who were applicants to the REC. In fact our interests were different: we wanted to provide a fair, transparent, collaborative and meaningful process, whilst applicants perceived interaction with the REC as an administrative exercise and they were solely interested in getting their proposals passed with no alterations. There was no interest in a wider debate on ethical issues and any challenges to academics' proposals were deemed to question professional competence. In the end, senior academic staff had the power to render the structures meaningless by undermining the overall credibility of the REC.

\section{Managing the unknown - the approach to qualitative research methods}

Tolich and Fitzgerald (2006: 71) state that, after a study of ethics committees in five countries, 'we have yet to find an ethics committee that reflects qualitative epistemological assumptions'. Hedgecoe (2008: 87) disputes this view as being 'largely historical'. However, our experience has been that 
misunderstandings still exist. Qualitative researchers accept the need for uncertainty in the research process and indeed it can be seen as a productive part of the process (Hoggett et al., 1994). Conversely, systems of research governance are designed within a deductive research context (van den Hoonaard, 2001), based on the premise that the world is knowable in advance and that outcomes can be predicted. An example of this is the requirement for consent through a form, whereas even when this has been granted, circumstances may change as the research emerges. This requirement fails to take into account the importance of re-establishing consent with participants on a regular basis rather than assuming ongoing consent due to a one-off signature (Ramcharan and Cutliffe 2001; White 2009).

Qualitative social science thus does not include a completely predetermined research design at an early stage (Truman, 2003; Connolly and Reid, 2007); ethics are situational and emerge through social relations; they are not something to be judged from a distance as a one-off endeavour (Rossiter et al., 2000; Hemmings, 2006; Armbruster, 2008). At worst, changes to research design can lead to multiple REC submissions; methodological inconsistencies; time lost and costs incurred; and, in extreme cases, complete abandonment of research (van den Hoonaard, 2001; Richardson and McMullan, 2007; Munro, 2008). An alternative perspective is that responding to the requirements of an ethics committee can lead a researcher to 'interrogate the cultural boundaries' of research practice (Hurdley, 2010: 522).

One of us had the experience of making an application for ethical approval for a qualitative research project from a REC consisting largely of academics with a physical science background. This involved a preliminary correspondence raising some issues about the application, followed by a decision in a closed session of the REC (to agree the application subject to minor amendments being made). The correspondence included a series of comments relating to the referencing, margins and project 
timetable, and including statements such as 'I understand that most of my comments are not about ethics, just the writing. No harm in making these suggestions' (annotated notes from REC member)².

Following these piecemeal observations, the REC discussed the proposal, a qualitative study of the lives of migrants. The data collection comprised in part of semi-structured interviews and focus groups. The comments made by the committee reveal 'trained incompetence' (Goffman, 1983). It required 'the inclusion of consent forms in English with assurances that other languages appropriate to the sample population will be created' (feedback from REC). In fact this can serve to bother prospective research participants depending on their own cultural norms. So for example migrants from Eastern Europe may be suspicious of forms believing that their signature could be used against them by unknown government agencies or figures of authority sometime in the future. Further the label 'sample population' is reflective of quantitative research. Concerns were also raised about access. Part of the research was an inquiry into the methodological issues associated with researching migrant communities and so it was planned to recruit migrants using two different approaches. The first was through a non-governmental organisation that provided support and the second was via employers. However the REC took issue with the latter method as 'it was felt that there may be an element of coercion in using the participants' employer as a gatekeeper to recruitment. It maybe (sic) possible for an NGO to be used as the contact' (feedback from REC). Finally, even though it had been indicated that issues of confidentiality and anonymity would be addressed, the committee advised that 'attention should also be given to issues regarding confidentiality, anonymity and protection of the data'. Not only did the REC appear not to fully consider the information already provided and also to understand the

\footnotetext{
${ }^{2}$ We regard it as ethical to quote from feedback provided for one of our own applications in this paper but not to quote material from applications made by others.
} 
nature of the research; it neglected the fact that the proposal had already been peer reviewed by two anonymous referees for the funding body. Further points were that the REC wished to see a 'broad schedule of the proposed questions or themes that will be addressed in both the interviews and focus groups' and (despite not having seen interview questions), they claimed it would be necessary to ensure that participants were able to avail of counselling.

The question may be raised of how different this was from the application made to the REC on which we were members. Indeed, the two experiences have in common that the applicants felt their integrity had been questioned by people who were not qualified to do so. A scrutiny of values, power and interests show some disparities, though. In this case, the values held by the REC were closely associated with the practice of quantitative research and, unlike the experience of Hedgecoe (2008), the members' lack of knowledge about qualitative approaches was not accepted. The interest of the applicant was, of course, to get the application agreed; but in this case the REC's interest appeared to be only in processing the application rather than in engaging in dialogue. And most importantly, in this case the researcher was a junior member of staff with no power to challenge the points made by the REC by, for example, raising them with a senior member of staff as had been done in the first example.

\section{Risk management, ethics and student dissertations}

A clash between the requirements of research governance and wider ethical awareness is also evident in our experience of the administration connected to undergraduate dissertations. We both have experience of dissertation supervision and one of us is responsible for co-ordination of an undergraduate dissertation module which includes ethical review of research proposals. However, somewhat like consent forms (Malone 2003:813; see also Truman 2003; Lincoln and Tierney, 2004), this 
is not a matter of reflective practice. It arises because our university is required to hold an up-to-date register of all research activity to ensure that the corporate insurance policy remains valid. Instead, ethical review is a legal solution that provides the institution with a safeguard if adverse events occur within that research. Specifically this allows the university to consider risks associated with research through the mandatory completion of ethical review forms by students. While most research involves some sort of risk, how that risk is defined is an interpretative act (Tierney and Corwin 2007) and so it is assessed by RECs as a probability. Completed in this way encourages students to consider ethics as a one-off proposition - they do ethics at a particular point in time and so do not feel the need to reconsider it throughout the research process and so may actually neglect to address ongoing ethical issues within the research.

Further having engaged in various discussions with a University administrator with responsibility for ethical issues it became clear that there was no common understanding of research ethics. For instance a suggestion that covert observation might be appropriate in some circumstances was not accepted by the administrator. Although students are taught to develop a wider perspective on ethics as part of a research methods course attached to the dissertation module, the process they have to undertake mitigates a deeper understanding of values and principles and replaces it with the completion of a form. We find that in this case the values of administrators predominate, implemented and to some extent moderated by academics through teaching and supervision. Because students, like staff applicants, wish their application to be approved without fuss, there is a temptation to carry out a simple project to fall into line with the interests of administrators; in particular, this may reduce innovative avenues of inquiry for brighter students. Power within the process lies with administrators and academics, students remain powerless as they have no input into the decision-making process. 


\section{Working together is possible - the 'good bureaucrat'}

Perhaps unusually, one of us has also had experience of working as a university administrator in the role of Research Support Officer (RSO). Something of a 'campus-level bureaucrat' (after Lipsky 1980) this was an all encompassing role that existed to provide support to academics as they pursued research funding and many policies existed because they were implemented by RSOs. But mindful of Lipsky, many of these policies were in fact vague and open to discretion. The cynic might describe the RSO function as a tool of University regulation as the process meant that academics were mostly unable to apply for or receive research awards without involvement from management. RSOs were one of the least admired positions on the campus and this may partially stem from their association with the loss of professional academic autonomy. However, officially at least, part of the job of the RSO was to ensure that paperwork was in order when academics applied for funding and subsequently if they were awarded research funding. This role was typically manifest through the RSO signature on applications and on associated letters of acceptance on behalf of the University. Although the position was low in the University hierarchy, RSOs were quite powerful.

One academic researcher had been awarded a grant and as part of the offer, the funding body requested that she demonstrated positive ethical review by the University. The RSO's perspective was that, as part of the University administration, the grant simply could not be accepted without evidence that the process of ethical approval was at least underway. Meanwhile the RSO was sympathetic to the novice academic's position - she was keen to ensure that her career was not jeopardised by failing to complete basic administrative functions. The process of obtaining ethical approval was not straightforward because at that time research governance was an emerging issue within academia and the only ethics committee was based in the Medical School. It did not accept that it had responsibility 
for applications from other parts of the university and there was no alternative procedure elsewhere; in the absence of effective procedures it fell to an individual to bridge the gap. After extensive liaison between the RSO, the academic concerned and the committee, the process was unravelled and ethical approval was granted, after close to a year. Eventually the researcher was able to conduct the research, albeit with a delayed start date.

This final perspective illustrates some interesting aspects of values, interests and power. Here, the professional autonomy of the academic became irrelevant within the arena of research governance. However, the interests of both parties - the RSO and the academic - lay in ensuring the grant was received: the RSO for the good of the university, and the academic for the good of her career as well as in order to carry out her research. Therefore both had an incentive to work together to ensure that the procedural barrier was removed. It was the RSO who had the power to do this, difficult though it was. This example shows how it is possible for administrators and academics to work together to achieve their respective goals in research governance. But critically, the process does not facilitate wider philosophical and normative discussions about research and ethics. Structural gaps remain within the framework and that is why simply addressing practical issues such as lack of co-operation or issues emerging due to evolving research agendas on an ad-hoc basis would be an inadequate response.

\section{Conclusions}

This article has reviewed the dilemmas of design and ownership involved in research ethics and research governance in the modern university and has reflected on the tactics adopted by academics in order to ensure that their research proposals gain ethical approval. We then gave some examples of the research governance process from various perspectives including REC member, REC Chair, applicant to a REC, 
lecturer with responsibility for students' ethics applications, student dissertation supervisor, and university administrator. We have shown that values, interests and power drive the outcomes of the situations described, and suggest that a closer alignment of these factors may help to increase collaboration and ensure both academic and administrative goals are met. The alternative, default, option is to continue with the present system, where ethical review is not valued, resulting in detachment and alienation, and where debate is at best constrained and at worst hostile. This situation perpetuates an understanding of ethics solely as a management tool within a broader regulatory framework. In so doing the role of the University as a contributor to wider social and cultural values (Scott 2004, Boden et al., 2009) is jeopardised.

Our experience shows that ethical regulation as currently practised runs counter to the collegiate ethos that still prevails within academic life. However, REC members are academics and some might argue that by integrating them into the REC, and by implication into the decision making structures of the school, greater control is exerted over researchers and research. Conversely, we argue that academics are in a strong position to shift current patterns by including the promotion of good practice within RECs; after all, academic freedom includes involvement in institutional governance (Tierney 1993; UNESCO 1997). An example would be by providing a forum for discussion of ethical issues to address themes such as what is meant by risk; applying the principle of beneficence; and power dilemmas. In this way, REC members can contribute to improved relations between the researched and researchers (Crow et al., 2006) but they can also encourage greater transparency (Richardson and McMullan, 2007) and ongoing reflective practice (White, 2009) among researchers. Perhaps most critically however is that such a collaborative approach takes account of the fact that ethics are 'relational and ultimately and inherently personal' (Boden et al. 2009: 746). To paraphrase Lipsky (1980), academics can do more than act as policy implementers - they can actually help to set the agenda and shape emergent practice. 
By considering ethics in this flexible manner, with due attention to the researched, researchers and a wider community; more philosophical discussions will flow, true academic freedom and collegiality will result. Academics will be able to divert their energies to exploring ethics for what they really are: as conduct in the research field with all of its inherent local, specific, contextual and contestable issues (Mauthner et al. 2002; Boden et al. 2009).

The process of ethical review must be something that is valued within the academic community, it must have significance. It requires movement away from a 'them and us' culture and from a 'ticky box' management style. Consequently we would argue that there is a need for honesty in what ethical review and research governance is about; at the end of the day, university administrators have goals and so do academics. We suggest there are two principles that could be followed in order to improve the current situation. First, ethical research practice should be part of the research culture, not a separate exercise. Research ethics committees should promote good practice as well as making decisions on individual applications. Somewhat like the way in which research groups achieve administrative duties for research assessment within the UK, RECs could develop a more beneficial role for all concerned. Secondly, RECs should recognise the expertise of the applicants and the different ways in which their chosen methodologies will lead them to interact with research participants. Committees should also recognise and acknowledge the limits of their own expertise and of their jurisdiction, seeking external advice or merely advising where appropriate.

Following these principles, ethical approval by a REC should be about collaboration between the different groups involved. We argue that this is preferable to a 'light touch' approach where boxes are ticked but ethical behaviour is not seriously contemplated. Optimistically we suggest that this might even liberate RECs to focus attention on more philosophical ethical matters. 
There are two important perspectives on the research process that we have omitted due to our lack of experience: funders and research participants. We have noted earlier that the reality of professional practice for research active staff is that they must compete for research grants and that therefore applications to their REC are a fact of life. We have been unable to find any significant, systematic research on the potential implications of the relationship between funders and researchers and this is an area in which further research is needed. For example, there are claims that researchers are put off undertaking certain types of research due to the difficulty of gaining ethical approval (Crow et al, 2006) but there is no analysis of the role funders may play in this decision by, perhaps, also being reluctant to fund difficult subjects areas.

Equally, we have noted the relative invisibility of research participants' views. Although both of us have been interviewed by others, neither has had the experience of substantial involvement in a research project as a participant. In the rare cases where participants' views have been explored (Truman, 2003; Graham et al., 2007; Hurdley, 2010; Grinyer, 2004), it is clear that participants have much to say for themselves and a more nuanced view of ethical practice than is recognised by RECs. Further work needs to be done to explore ways of incorporating participants' opinions into the research governance process.

Shifting from a purely regulatory to a collaborative approach is not without its problems. It requires additional time to conduct meaningful meetings with researchers, potentially research participants and reviewers. There may be resistance to a re-integration of research ethics into research culture, due to current experiences of RECs; academics must take control of this process and re-orientate RECs towards professional rather than administrative practice. It would be naive to argue that the collaborative model 
eliminates all of the problems associated with current practice. Nonetheless collaboration goes some way to bridge a growing divide between diktat and practice. It offers the prospect of removing the alienation of social researchers from anything to do with ethics, with potentially serious consequences for the ethical standards of research and may also serve to redress the loss to academic autonomy.

\section{Acknowledgements}

The authors would like to thank Paul J. Maginn of the University of Western Australia for discussions which helped to develop the ideas in this paper. Thanks are also due to the three anonymous referees. 


\section{References}

Armbruster, H. (2008) Introduction. The Ethics of Taking Sides in Armbruster, H and Laerke, A. (eds) Taking Sides: Ethics, Politics, and Fieldwork in Anthropology, pp.1-22. New York and Oxford: Berghahn Books.

Boden,R., Epstein, D. and Latimer, J. (2009) Accounting for ethos or programmes for conduct? The brave new world of research ethics committees. The Sociological Review, 57(4) pp.727-749.

BSA (2004) Statement of Ethical Practice for the British Sociological Association, Durham: British Sociological Association.

Cannella, G. S. and Lincoln, Y.S (2007) Predatory vs. Dialogic Ethics: Constructing an Illusion or Ethical Practice as the Core of Research Methods. Qualitative Inquiry; 13(3) pp.315-335

Cole, A., and Knowles, J.G. (2001). Lives in context: The art of life history research. Walnut Creek, CA: Altamira.

Coomber, R. (2002) Signing your life away?: Why research ethics committees (REC) shouldn't always require written confirmation that participants in research have been informed of the aims of a study and their rights - the case of criminal populations (Commentary). Sociological Research Online Vol.

7(1) http://www.socresonline.org.uk/7/1coomber.html, last accessed 07.08.09) 
Connolly, K. and Reid, A. (2007) Ethics review for qualitative inquiry: adopting a values-based facilitative approach. Qualitative Inquiry; 13(7) pp.1031-1047

Crow, G., Wiles, R., Heath, S. and Charles, V. (2006) 'Research Ethics and Data Quality:

The Implications of Informed Consent', International Journal of Social Research Methodology, 9(2): 8395.

de Laine, M. (2000) Fieldwork, Participation and Practice: Ethics and Dilemmas in Qualitative Research, London: Sage.

Department of Health (2004) The research governance framework for health and social care: Implementation plan for social care. London: DoH.

Dolan, B. (1999) The impact of local research ethics committees on the development of nursing knowledge. Journal of Advanced Nursing Vol. 30 (5) pp.1009-10.

ESRC (2005) Research Ethics Framework. Swindon: Economic and Social Research Council. Available at http://www.esrc.ac.uk/ESRCInfoCentre/Images/ESRC Re Ethics Frame tcm6-11291.pdf, last accessed 07.08.09)

ESRC (2010) Framework for Research Ethics. . Swindon: Economic and Social Research Council. Available at:http://www.esrcsocietytoday.ac.uk/ESRCInfoCentre/Images/Framework\%20for\%20Research\%20Ethi cs\%202010 tcm6-35811.pdf last accessed 20.12.10 
Flyvberg, B. (2001) Making Social Science Matter: Why Social Inquiry Fails and How it can Succeed Again. Cambridge: Cambridge University Press

Goffman, E (1983) The Interaction Order, Presidential Address to American Sociological Association, in Lemert, C. and Branaman, A. (eds) The Goffman Reader (1997) Malden, Massachusetts: Blackwell Publishers.

Gosling D (2004): “Critical change consultants for higher education" in Illingworth S (ed) Approaches to ethics in higher education: teaching ethics across the curriculum. Leeds: Philosophical and Religious Studies Subject Centre Learning and Teaching Support Network, University of Leeds.

Graham, J., Grewal, I. and Lewis, J. (2007) Ethics in Social Research: the views of research participants. London: Government Social Research Unit.

Grinyer, A. (2004) 'The Narrative Correspondence Method: What a Follow-Up Study Can Tell Us about the Longer Term Effect on Participants in Emotionally Demanding Research', Qualitative Health Research 14(10): 1326-1341.

Hammersley, M. (2009) Against the ethicists: on the evils of ethical regulation. International Journal of Social Research Methodology. Vol. 12(3) pp.211-225.

Hedgecoe, A. (2008) Research Ethics Review and the Sociological Research Relationship. Sociology Vol. 42(5) pp.873-886. 
Hemmings, A. (2006) Great Ethical Divides: Bridging the gap between institutional review boards and researchers. Educational Researcher Vol. 35 pp.12-18.

Higher Education Statistics Agency (2005) Resources of Higher Education Institutions 2003/04 Available at http://www.hesa.ac.uk/index.php/content/view/1905/251/ , last accessed 16.02.11)

Higher Education Statistics Agency (2011) Statistical First Release 154 Available at http://www.hesa.ac.uk/index.php, last accessed 16.02.11)

Hoggett, P., Jeffers, S. and Harrison, L. (1994) 'Reflexivity and uncertainty in the research process', Policy and Politics, Vol. 22 no.1, pp.59-70.

Humphries, B. (2000) Unsettling ethics in social research in Blasius, J., Hox, J., de Leeuw, J. and Schmidt, P (eds.) Social Science Methodology in the New Millennium. Cologne: TT-Publikaties (CD ROM).

Hurdley, R. (2010) 'In the Picture or Off the Wall? Ethical Regulation, Research Habitus, and Unpeopled Ethnography', Qualitative Inquiry 16(6): 517-528.

Israel, M. and Hay, I. (2006) Research Ethics for Social Scientists London: Sage.

Kent, J., Williamson, E., Goodenough, T. and Ashcroft, R. (2002) Social Science Gets the Ethics Treatment: Research governance and ethical review, Sociological Research Online Vol. 7 no. 4, http://www.socresonline.org.uk/7/4/williamson.html 
Lincoln, Y.S. and Tierney, W.G. (2004) Qualitative research and institutional review boards. Qualitative Inquiry Vol.10(2) pp.219-234.

Lipsky, M. (1980) Street-Level Bureaucracy: Dilemmas of the Individual in Public Services. New York, Sage.

Malone, S. (2003) Ethics at home: informed consent in your own backyard. Qualitative studies in Education Vol. 16(6) pp.797-815.

Mauthner, M., Birch, M., Jessop, J. and Miller, T. (2002) Ethics in Qualitative Research, London: Sage.

Munro, E. (2008) 'Research Governance, Ethics and Access: A Case Study Illustrating the new Challenges Facing Social Researchers', International Journal of Social Research Methodology 11(5): 429-439.

Punch, M. (1998) 'Politics and Ethics in Qualitative Research', in Denzin, N.K. and Lincoln, Y.S. (eds.) The Landscape of Qualitative Research, Thousand Oaks: Sage.

Ramcharan, P. and Cutliffe, J.R. (2001) Judging the ethics of qualitative research: considering the 'Ethics as process' model. Health and Social Care in the Community Vol.9 (6) pp.358-66.

Richardson, S. and McMullan, M. (2007) Research Ethics in the UK: What can sociology learn from health? Sociology Vol. 41(6) pp.1115-1132 
Rossiter, A., Prilleltensky, I. and Walsh-Bowers, R. (2000) A postmodern perspective on professional ethics in Fawcett, B., Featherstone, B., Fook, J. and Rossiter, A. (eds.) Practice and Research in Social Work: postmodern feminist perspectives. London and New York: Routledge.

Scott, P. (2004) Ethics 'in' and 'for' Higher Education. Higher Education in Europe Vol. 29 (4) pp. 439-450.

Shortland, S. 2004. Peer observation: A tool for staff development or compliance? Journal of Further and Higher Education 28, no. 2: 219-28.

Sin, C.H. (2005) Seeking informed consent: reflections on research practice. Sociology Vol 39(2) pp. 27794.

SRA (2003) Ethical guidelines, London: Social Research Association.

Tierney, W.G. and Corwin, B.Z. (2007) The tensions between academic freedom and institutional review boards. Qualitative Inquiry; 13(3) pp.388-398.

Tierney, W. G. (1993). Academic freedom and the parameters of knowledge. Harvard Educational Review, 63(2), 143-160.

Tolich, M. and Fitzgerald, M.H. (2006) If Ethics Committees Were Designed For Ethnography Journal of Empirical Research on Human Research Ethics 1: 71-78. 
Truman, C. (2003) Ethics and the ruling relations of research production. Sociological Research Online, Vol.8 No.1, http://www.socresonline.org.uk/8/1/truman.html

UNESCO (1997) Recommendation concerning the Status of Higher-Education Teaching Personnel. Paris: United Nations Educational, Scientific and Cultural Organization

van den Hoonaard, W.C. (2002) Walking the tightrope: Ethical issues for qualitative researchers. Toronto: University of Toronto Press.

Warlow, C. (2004) Clinical research under the cosh again. British Medical Journal Vol.329 pp.241-2.

White, L. (2009) Challenge of research ethics committees to the nature of operations research. Omega Vol 37 pp.1083-1088.

Yearley, S. (2005) Making Sense of Science. Understanding the social study of science. London: Sage 